\title{
Treating multiple sclerosis and neuromyelitis optica spectrum disorder during the COVID-19 pandemic
}

Wallace Brownlee, PhD, FRACP, Dennis Bourdette, MD, Simon Broadley, PhD, FRACP, Joep Killestein, PhD, and Olga Ciccarelli, PhD, FRCP

Neurology ${ }^{\circledR}$ 2020;94:949-952. doi:10.1212/WNL.0000000000009507

The emergence of novel coronavirus 2019 (COVID-19) ${ }^{1}$ and the subsequent pandemic present a unique challenge to neurologists managing patients with multiple sclerosis (MS) and related neuroinflammatory disorders, such as neuromyelitis spectrum disorder (NMOSD).

National professional bodies (e.g., Italian Society of Neurology and Association of British Neurologists) and patient organizations (e.g., National MS Society, MS International Federation, UK MS Society, and MS Australia) have responded rapidly by issuing guidelines for the COVID-19 pandemic, primarily focused on MS disease-modifying therapies (DMTs). In this commentary, we highlight the implications of COVID-19 for people with MS and related disorders, including the risk of respiratory infections, general health advice, and recommendations (from consensus-based guidelines) for immunotherapies, relapse management, and service delivery during the COVID-19 pandemic.

\section{Risk of respiratory infections}

Whether people with MS and NMOSD are at an increased risk of COVID-19 infection or at a higher risk of more severe infection is unknown. There are no data available on whether the rate of mild, self-limiting respiratory infections that do not require a medical encounter is increased in people with MS. However, there is increased infection-related health care utilization across all age groups in people with MS compared with the general population. ${ }^{2}$ These infections include pneumonia ${ }^{2,3}$ (particularly in people with bulbar weakness resulting in aspiration and impaired pulmonary function due to severe quadriparesis) and influenza, ${ }^{3}$ but not upper respiratory tract infections. ${ }^{2}$ Older age, male sex, worse physical disability, and lower socioeconomic status are associated with increased hospitalization rates in MS. ${ }^{3}$ People with MS have a higher risk of intensive care unit admission with infections and higher 1-year mortality after admission than the general population. ${ }^{4}$ In addition to the higher background risk of infection-related health care utilization, people with MS treated with the secondgeneration DMTs are exposed to a further increased risk of infections. ${ }^{5}$ These factors should be considered when counseling individuals about the risks of COVID-19 infection.

\section{General health advice}

People with MS and related disorders should follow World Health Organization (WHO) and national or local health authority guidance on preventive measures to reduce transmission of COVID-19 in the general population. These include social distancing, frequent hand washing with soap and water or an alcohol-based hand rub, and respiratory hygiene. Advice from the WHO is updated regularly (who.int/emergencies/diseases/novel-coronavirus-2019).

\author{
Correspondence \\ Dr. Brownlee \\ w.brownlee@ucl.ac.uk
}

\section{MORE ONLINE}

\section{COVID-19 Resources}

For the latest articles, invited commentaries, and blogs from physicians around the world NPub.org/COVID19

From the Department of Neuroinflammation (W.B., O.C.), Queen Square MS Centre, UCL Queen Square Institute of Neurology, London, United Kingdom; Department of Neurology (D.B.), Oregon Health \& Science University, Portland, OR; Menzies Health Institute Queensland (S.B.), Griffith University, Gold Coast Campus, Queensland, Australia; Department of Neurology (J.K.), Amsterdam University Medical Center, Amsterdam, the Netherlands; and University College London Hospitals NIHR Biomedical Research Centre (O.C.), London, United Kingdom.

Go to Neurology.org/N for full disclosures. Funding information and disclosures deemed relevant by the authors, if any, are provided at the end of the editorial. 
Patients should be educated about the symptoms of COVID-19 infection, including fever, cough, and shortness of breath. People with MS and related disorders should be advised not to make changes to their MS treatment without discussion with their neurologist.

\section{Managing patients with COVID-19 infection}

In people with MS and related disorders taking immunotherapy, treatment is generally continued during mild, viral infections. In those with documented mild COVID-19 infection, it may be reasonable to continue treatment. Neurologists should have a lower threshold for stopping treatment in people taking therapies with greater immunosuppressive effects and those with risk factors for a more severe disease (older age and comorbidities ${ }^{6}$ ) or if COVID-19 symptoms are deteriorating.

Consideration should be given to stopping treatment in those who are hospitalized with severe or complicated COVID-19 infection. Treatment can be restarted after 4 weeks or when symptoms have fully resolved, keeping in mind the risk of rebound MS activity with S1P modulators and natalizumab. Neurologists should alert intensive care physicians to the importance of fever management in people with MS.

\section{Managing patients with MS without COVID-19 infection}

\section{Acute relapses}

MS relapses are frequently treated with a short course of highdose IV methylprednisolone. Chronic use of corticosteroids is associated with an increased risk of infections, and short-term use of high-dose corticosteroids may increase the risk of herpes virus reactivation. ${ }^{7}$ High-dose steroids hasten the recovery from MS relapses, but do not influence the final degree of recovery. ${ }^{8}$ Neurologists should consider having a higher threshold for offering steroid treatment during the COVID-19 pandemic.

An acute infection will sometimes lead to a transient worsening of symptoms in MS and other disorders (pseudo-relapse). ${ }^{9}$ Patients should be carefully screened for symptoms of active COVID-19 infection before receiving corticosteroid treatment.

\section{Disease-modifying therapies}

A few MS therapies (interferon- $\beta$ and glatiramer acetate) exert immunomodulatory effects with no increase in the risk of systemic infections. Other treatments used in contemporary MS practice do have immunosuppressive effects with alterations in lymphocyte number, trafficking, proliferation, and function, ${ }^{9}$ with an increased risk of infections, including viral infections and respiratory infections. ${ }^{7,9}$ It is reasonable to hypothesize that these therapies may predispose to a greater risk of COVID-19 infection and potentially more severe infection. However, at the present time, there is no evidence to support this. People with MS who are profoundly lymphopenic, for example, after treatment with alemtuzumab or less commonly during treatment with cladribine, fingolimod, or dimethyl fumarate, may be at a higher risk.

In most people with MS, the benefits of continuing treatment will outweigh the risks of stopping an MS therapy because of concerns over COVID-19 (table). Alemtuzumab and, to a lesser extent, cladribine lead to a transient and variable period of lymphopenia after each course of treatment. We recommend delaying treatment with these therapies in patients due to receive a second or subsequent course (table). AntiCD20 therapies, including ocrelizumab and rituximab, are typically dosed regularly every 6 months. B-cell depletion frequently lasts much longer than the scheduled dosing interval, and extended-interval dosing should be considered, especially in patients who are B cell depleted (as measured by CD19/CD20 lymphocyte counts) at the time of the next scheduled dose or those with low levels of immunoglobulin G. Extended-interval dosing is already widely used in patients treated with natalizumab because of observational data showing a reduced risk of progressive multifocal leukoencephalopathy. ${ }^{10}$ Whether this approach reduces the risk of other infections is unknown, but should be considered during the COVID-19 pandemic to reduce hospital visits.

The counseling of patients with MS who want to discuss delaying or even stopping an MS therapy will be influenced by (1) patient factors, such as age and comorbidities that increase the risk of severe COIVD-19 infection ${ }^{6}$; (2) disease factors, including disease activity before starting treatment and in the previous 12 months, disease course, and disability; and (3) drug factors, including the potential for rebound disease activity if treatment is stopped (e.g., S1P modulators and natalizumab).

Decisions over initiation or switching DMTs during the COVID-19 pandemic should take into account the same patient, disease, and drug factors noted above. It is safe to initiate treatment with interferon- $\beta$ and glatiramer acetate and perhaps safe to start teriflunomide and dimethyl fumarate in children and young adults who are otherwise healthy (table). The burden of treatment monitoring should be taken into account when initiating a new MS therapy, for example, monthly (or 2-weekly in Europe) liver function tests in patients starting teriflunomide may be impractical during the COVID-19 pandemic. If a high-efficacy treatment is required for patients with severe or breakthrough disease, starting or switching to natalizumab is preferable to alemtuzumab, cladribine, or ocrelizumab because the risk of systemic immunosuppression is lower and prolonged lymphocyte depletion does not occur. Treatment with natalizumab for 12-18 months is associated with a low risk of progressive multifocal leukoencephalopathy (including in patients who are JC virus antibody positive) and can be considered as a bridging therapy. There is a general consensus against autologous 
Table Recommendations for use of multiple sclerosis disease-modifying therapies during the COVID-19 pandemic

\begin{tabular}{|c|c|c|}
\hline & Patients initiating treatment & Patients already on treatment \\
\hline \multicolumn{3}{|l|}{$\begin{array}{l}\text { No risk of systemic } \\
\text { immunosuppression }\end{array}$} \\
\hline Interferon- $\beta$ preparations & Initiate treatment as usual & Continue treatment \\
\hline Glatiramer acetate & Initiate treatment as usual & Continue treatment \\
\hline \multicolumn{3}{|l|}{$\begin{array}{l}\text { Low risk of systemic } \\
\text { immunosuppression }\end{array}$} \\
\hline Teriflunomide & Initiate treatment as usual & Continue treatment; ensure neutrophil count $>1,000 / \mathrm{mm}^{3}$ \\
\hline Dimethyl fumarate & Initiate treatment as usual & Continue treatment; ensure lymphocyte count $>500-800 / \mathrm{mm}^{3 a}$ \\
\hline Natalizumab & Initiate treatment as usual & Continue treatment; consider extended-interval dosing \\
\hline \multicolumn{3}{|l|}{$\begin{array}{l}\text { Moderate risk of systemic } \\
\text { immunosuppression }\end{array}$} \\
\hline $\begin{array}{l}\text { S1P modulators, e.g., } \\
\text { fingolimod, siponimod, } \\
\text { and ozanimod }\end{array}$ & $\begin{array}{l}\text { Consider delaying initiation of treatment or an } \\
\text { alternative DMT, taking into account the risks and } \\
\text { benefits }\end{array}$ & Continue treatment; ensure lymphocyte count $>200-300 / \mathrm{mm}^{3 a}$ \\
\hline $\begin{array}{l}\text { Anti-CD20 agents, e.g., } \\
\text { ocrelizumab and } \\
\text { rituximab }\end{array}$ & $\begin{array}{l}\text { Consider delaying initiation of treatment or an } \\
\text { alternative DMT, taking into account the risks and } \\
\text { benefits }\end{array}$ & $\begin{array}{l}\text { Consider extended-interval dosing guided by CD19 lymphocyte } \\
\text { counts, taking into account the risks and benefits, and reassess } \\
\text { periodically }\end{array}$ \\
\hline \multicolumn{3}{|l|}{$\begin{array}{l}\text { High risk of systemic } \\
\text { immunosuppression }\end{array}$} \\
\hline Cladribine & $\begin{array}{l}\text { Do not initiate treatment, consider an alternative } \\
\text { DMT }\end{array}$ & $\begin{array}{l}\text { Delay further courses of treatment, taking into account the risks } \\
\text { and benefits, and reassess periodically }\end{array}$ \\
\hline Alemtuzumab & $\begin{array}{l}\text { Do not initiate treatment, consider an alternative } \\
\text { DMT }\end{array}$ & $\begin{array}{l}\text { Delay further courses of treatment, taking into account the risks } \\
\text { and benefits, and reassess periodically }\end{array}$ \\
\hline $\begin{array}{l}\text { Autologous hematopoietic } \\
\text { stem cell transplantation }\end{array}$ & $\begin{array}{l}\text { Do not initiate treatment, consider an alternative } \\
\text { DMT }\end{array}$ & Not applicable \\
\hline
\end{tabular}

Abbreviation: DMT = disease-modifying therapy.

a Some neurologists advise dose reduction if lymphocyte counts are approaching cutoff values for discontinuing treatment, although no evidence is available to guide these decisions.

hematopoietic stem cell transplantation, as it represents the highest risk of infections to patients.

\section{Managing patients with neuromyelitis optica spectrum disorder without COVID-19 infection}

Relapses in patients with NMOSD may be devastating, and patients should be encouraged to continue therapies for attack prevention including corticosteroids, azathioprine, mycophenolate mofetil, rituximab, tocilizumab, and eculizumab. If there is a clinical need to stop or delay treatment in patients with NMOSD, moderate-dose corticosteroids (e.g., prednisolone 20 $\mathrm{mg}$ ) can be used to prevent relapses in the short to medium term.

\section{Managing special patient groups}

The risk of COVID-19 infection appears lower in children, and infections appear milder. There are no special considerations in children with MS and related disorders. ${ }^{11}$ Severe COVID-19 infections are more common in older adults (aged $>60$ years) with a higher case fatality rate. ${ }^{6}$ Treatment decisions in this age group should be individualized, taking into account other comorbidities that increase the risk of death (cardiorespiratory disease and diabetes $)^{6}$ and the more modest benefits of diseasemodifying treatment in older patients ${ }^{12}$ and/or those with progressive forms of MS. Pregnant women should follow general health advice during the COVID-19 pandemic, with no special considerations.

\section{Implications for service delivery}

Many MS centers are using telemedicine to avoid nonessential hospital visits during the COVID-19 pandemic. Telemedicine has previously been validated as a tool for assessing disability in MS with high patient acceptability. ${ }^{13}$ Other steps to reduce hospital visits such as home delivery of medications, delaying follow-up MRI scans in stable patients, and reducing the frequency of routine laboratory monitoring should also be considered. Oral corticosteroids may be 
preferable to treat acute relapses, given the equivalent efficacy to IV corticosteroids, at least in patients with MS. ${ }^{14}$ Less frequent dosing of infusion therapies (e.g., natalizumab and ocrelizumab) may also relieve pressure on infusion centers that may be understaffed due to redeployment or illness. MRI and infusion centers have implemented additional measures to reduce the risk of COVID-19 transmission in these settings.

\section{Conclusions}

As for the general population, most patients with MS are expected to experience only mild symptoms with COVID-19 infection. Some immunotherapies may increase the risk of more severe infection and individualized risk assessment is required, taking into account the immunosuppressive effects of the treatment and other patient factors (e.g., age, physical disability, and comorbidities) and the health care setting. Collecting data on the impact of COVID-19 on people with MS and related disorders and particularly the risks of a novel pathogen in patients on immunosuppressive treatments is a priority for national and international registries. We would recommend all neurologists who become aware of a person with MS being confirmed as COVID-19 positive notify their local registry.

\section{Study funding}

No targeted funding reported.

\section{Disclosure}

W. Brownlee has accepted speaker honoraria and/or participated in advisory boards for Biogen, Merck, Mylan, Novartis, Roche, and Sanofi Genzyme. D. Bourdette has received consultation fees from Magellan Health and has research grants from the National MS Society. S. Broadley has accepted speaker and/or advisory board honoraria and travel sponsorship from Bayer Schering, Biogen Idec, Merck, Novartis, and Sanofi Genzyme; has been an investigator in clinical trials sponsored by Biogen Idec, Novartis, and Genzyme; and was the recipient of an unencumbered research grant from Biogen Idec. J. Killestein has accepted speaker and consulting fees from Merck, Biogen, Teva, Sanofi, Genzyme, Roche, and Novartis. O. Ciccarelli has acted as a consultant for Roche, Novartis, and Merck in the last 12 months. She is supported by the National Institute for Health Research (NIHR) University College London Hospitals (UCLH) Biomedical Research Centre (BRC), London, United Kingdom. She is the Deputy Editor of Neurology. Go to Neurology.org/N for full disclosures.

\section{References}

1. Zhu N, Zhang D, Wang W, et al. A novel coronavirus from patients with pneumonia in China, 2019. N Engl J Med 2020;382:727-733.

2. Wijnands JM, Kingwell E, Zhu F, et al. Infection-related health care utilization among people with and without multiple sclerosis. Mult Scler 2017;23:1506-1516.

3. Marrie RA, Elliott L, Marriott J, et al. Dramatically changing rates and reasons for hospitalization in multiple sclerosis. Neurology 2014;83:929-937.

4. Marrie RA, Bernstein CN, Peschken CA, et al. Intensive care unit admission in multiple sclerosis: increased incidence and increased mortality. Neurology 2014;82: 2112-2119.

5. Wijnands JMA, Zhu F, Kingwell E, et al. Disease-modifying drugs for multiple sclerosis and infection risk: a cohort study. J Neurol Neurosurg Psych 2018;89: $1050-1056$

6. Novel Coronavirus Pneumonia Emergency Response Epidemiology Team. Vital surveillances: the epidemiological characteristics of an outbreak of 2019 novel coronavirus diseases (COVID-19) —China, 2020. China CDC Weekly. Available at: weekly.chinacdc.cn/en/. Accessed March 26, 2020.

7. Winkelmann A, Loebermann M, Reisinger EC, Hartung HP, Zettl UK. Diseasemodifying therapies and infectious risks in multiple sclerosis. Nat Rev Neurol 2016; 12:217-233.

8. Beck RW, Cleary PA, Anderson MM, et al. A randomized, controlled trial of corticosteroids in the treatment of acute optic neuritis. N Engl J Med 1992;326:581-588.

9. De Angelis F, John NA, Brownlee WJ. Disease-modifying therapies for multiple sclerosis. BMJ 2018;363:k4674.

10. Ryerson LZ, Foley J, Chang I, et al. Risk of natalizumab-associated PML in patients with MS is reduced with extended interval dosing. Neurology 2019;93:e1452-e1462.

11. Multiple Sclerosis International Federation. Global COVID-19 advice for people with MS. Available at: msif.org/. Accessed March 26, 2020.

12. Weideman AM, Tapia-Maltos MA, Johnson K, Greenwood M, Bielekova B. Metaanalysis of the age-dependent efficacy of multiple sclerosis treatments. Front Neurol 2017;8:577.

13. Bove R, Bevan C, Crabtree E, et al. Toward a low-cost, in-home, telemedicine-enabled assessment of disability in multiple sclerosis. Mult Scler 2019;25:1526-1534.

14. Le Page E, Veillard D, Laplaud DA, et al. Oral versus intravenous high-dose methylprednisolone for treatment of relapses in patients with multiple sclerosis (COPOUSEP): a randomised, controlled, double-blind, non-inferiority trial. Lance Neurol 2015;386:974-981. 


\section{Neurology}

\section{Treating multiple sclerosis and neuromyelitis optica spectrum disorder during the COVID-19 pandemic}

Wallace Brownlee, Dennis Bourdette, Simon Broadley, et al. Neurology 2020;94;949-952 Published Online before print April 2, 2020

DOI 10.1212/WNL.0000000000009507

\section{This information is current as of April 2, 2020}

\section{Updated Information \&} Services

References

Citations

Permissions \& Licensing

Reprints including high resolution figures, can be found at: http://n.neurology.org/content/94/22/949.full

This article cites 12 articles, 5 of which you can access for free at: http://n.neurology.org/content/94/22/949.full\#ref-list-1

This article has been cited by 3 HighWire-hosted articles: http://n.neurology.org/content/94/22/949.full\#\#otherarticles

Information about reproducing this article in parts (figures,tables) or in its entirety can be found online at:

http://www.neurology.org/about/about_the_journal\#permissions

Information about ordering reprints can be found online:

http://n.neurology.org/subscribers/advertise

Neurology ${ }^{\circledR}$ is the official journal of the American Academy of Neurology. Published continuously since 1951 , it is now a weekly with 48 issues per year. Copyright @ 2020 American Academy of Neurology. All rights reserved. Print ISSN: 0028-3878. Online ISSN: 1526-632X.

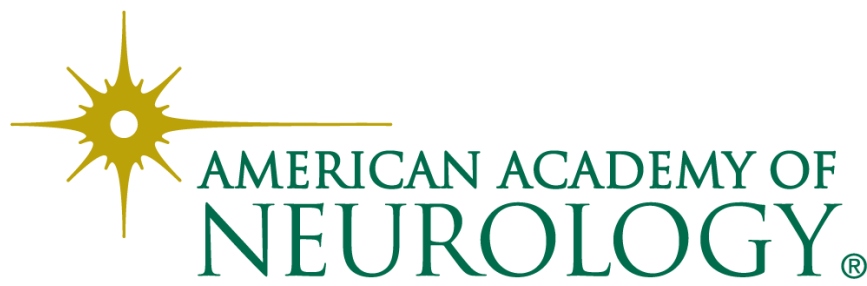

